\title{
Left ventricular geometry and endogenous ouabain in a Flemish population
}

\author{
Tatiana Kuznetsova $^{\mathrm{a}}$, Paolo Manunta ${ }^{\mathrm{b}}$, Nunnzia Casamassima ${ }^{\mathrm{b}}$, \\ Elisabetta Messaggio ${ }^{\mathrm{b}}$, Yu Jin $^{\mathrm{a}}$, Lutgarde Thiijs ${ }^{\mathrm{a}}$, Tom Richart ${ }^{\mathrm{a}, \mathrm{c}}$, \\ Robert H. Fagard ${ }^{\mathrm{a}}$, Giuseppe Bianchi ${ }^{\mathrm{b}}$ and Jan A. Staessen ${ }^{\mathrm{a}, \mathrm{c}}$
}

Background Endogenous ouabain, an endogenous digitalis-like steroid, is synthesized in the adrenal glands and possibly in the hypothalamus. In vitro and in vivo, endogenous ouabain triggers growth and proliferation of cardiomyocytes.

Objective We therefore investigated the association between left ventricular structure and function and plasma endogenous ouabain in a general population.

Methods We randomly recruited 536 individuals from a general population ( $50.7 \%$ women, mean age 53.1 years). Measurements included echocardiographic left ventricular structure and function, blood pressure, plasma endogenous ouabain, and the 24-h urinary excretion of sodium.

Results The geometric mean plasma endogenous ouabain was $95.5 \mathrm{pmol} / \mathrm{l}$ (interquartile range 79.4-120.2 pmol/l). We expressed effect sizes for a 1-SD increase in plasma endogenous ouabain ( 0.21 on the logarithmic scale), while accounting for important covariables. For a 1-SD increment in plasma endogenous ouabain, SBP, left ventricular posterior wall, the interventricular septum, and relative wall thickness increased by $1.59 \mathrm{mmHg}(P=0.009), 0.138 \mathrm{~mm}$ $(P=0.003), 0.152 \mathrm{~mm}(P=0.013)$, and $0.71 \times 10^{-2}$ $(P=0.008)$, respectively. In a sensitivity analysis, involving 431 individuals aged $29-71$ years (10-90th percentile interval), a 1-SD increase in plasma endogenous ouabain was associated with opposite trends in ejection fraction $(+0.90 \%, P=0.005)$ and left ventricular systolic longitudinal

\section{Introduction}

In 1982, Hamlyn et al. [1] demonstrated for the first time that a factor circulating in human plasma inhibited purified $\mathrm{Na}+, \mathrm{K}+$-ATPase and was correlated with higher blood pressure (BP). This observation initiated further research on endogenous digitalis-like steroids such as cardenolides and bufadienolides [2]. Endogenous ouabain is synthesized in the adrenal glands and possibly in the hypothalamus. Functionally, endogenous ouabain is a high-affinity, reversible, and specific inhibitor of the sodium pump, with inotropic and vasopressor activity [3]. In addition, endogenous ouabain activates signal transduction via the Src-epidermal growth factor receptor (EGFr)-extracellular signal-regulated kinase (ERK) pathway, and thereby triggers growth and proliferation of strain $(-0.48 \%, P=0.011)$. Moreover, in individuals whose sodium excretion was above median $(160 \mathrm{mmol} / 24 \mathrm{~h})$, the aforementioned associations reached a higher level of statistical significance.

Conclusion Our population-based study suggested that endogenous ouabain might have a trophic effect on the myocardium, independent of blood pressure and other covariables. The clinical implication of these findings remains to be elucidated. $J$ Hypertens 27:1884-1891 (c) 2009 Wolters Kluwer Health | Lippincott Williams \& Wilkins.

Journal of Hypertension 2009, 27:1884-1891

Keywords: echocardiography, epidemiology, left ventricular remodelling, ouabain

Abbreviations: FLEMENGHO, Flemish Study on Environment, Genes and Health Outcomes; LV, left ventricular; RWT, relative wall thickness; TDI, tissue Doppler imaging

astudies Coordinating Centre, Division of Hypertension and Cardiovascular Rehabilitation, Department of Cardiovascular Diseases, University of Leuven, Leuven, Belgium, ${ }^{b}$ Divisione di Nefrologia, Dialisi e Ipertensione, Univerisitá VitaSalute, Milan, Italy and ${ }^{\mathrm{C} D e p a r t m e n t}$ of Epidemiology, University of Maastricht, Maastricht, The Netherlands

Correspondence to Jan A. Staessen, M.D., Ph.D., F.A.H.A., F.E.S.C., Studies Coordinating Centre, Division of Hypertension and Cardiovascular Rehabilitation, Department of Cardiovascular Diseases, University of Leuven, Campus Gasthuisberg, Herestraat 49, Box 702, B-3000 Leuven, Belgium

Tel: +32 1634 7104; fax: +32 1634 7106; e-mail: jan.staessen@med.kuleuven.be

Received 2 March 2009 Revised 12 May 2009

Accepted 18 May 2009

renal tubular cells and cardiomyocytes in vitro and in vivo, even at subnanomolar concentrations [4].

In never-treated [5] and untreated [6] hypertensive patients, left ventricular (LV) mass, stroke volume (SV), and relative wall thickness (RWT) increased and heart rate (HR) decreased with higher circulating endogenous ouabain level. In some studies, nearly $50 \%$ of patients with uncomplicated essential hypertension have elevated plasma endogenous ouabain [6]. Both LV remodelling and hypertension are important risk factors for congestive heart failure. To our knowledge, no population study has described the association between LV structure and function and plasma endogenous ouabain. We therefore investigated this 
association in individuals randomly selected from a Belgian population.

\section{Methods}

\section{Study participants}

The Ethics Committee of the University of Leuven approved the Flemish Study on Environment, Genes and Health Outcomes (FLEMENGHO) [7]. As described elsewhere [7,8], from August 1985 until December 2005, we identified a random population sample stratified by sex and age from a geographically defined area in northern Belgium. The seven municipalities gave listings of all inhabitants sorted by address. Households, defined as those who lived at the same address, were the sampling unit. We numbered households consecutively, and generated a random-number list by use of the SAS random function (SAS Institute, Cary, North Carolina, USA). Households with a number matching the list were invited; household members older than 18 years were eligible.

From June 2005 until June 2008, we re-invited 845 former participants for a follow-up examination at our field centre, including echocardiography. After excluding 25 patients who were bedridden or institutionalized, we obtained informed written consent from 667 participants (participation rate $81.3 \%$ ). We excluded 51 individuals because of $\mathrm{LV}$ remodelling due to myocardial infarction or coronary revascularization $(n=16)$; valvular heart disease $(n=27)$; atrial fibrillation $(n=6)$, or the presence of an artificial pacemaker $(n=2)$. We discarded a further 80 individuals from analysis because of missing endogenous ouabain measurements $(n=75)$ or because the echocardiogram was of insufficient quality $(n=5)$ Thus, the total number of participants statistically analyzed was 536 .

\section{Echocardiography}

The participants refrained from smoking, heavy exercise, or drinking alcohol or caffeine-containing beverages for at least $3 \mathrm{~h}$ before echocardiography. The BP during echocardiography was the average of two readings, obtained with a validated OMRON 705IT device (Omron Corp., Tokyo, Japan) at the end of the examination.

\section{Data acquisition}

One experienced physician (T.K.) did the ultrasound examination according to the recommendations of the American Society of Echocardiography [9] using a Vivid7 Pro (GE Vingmed, Horten, Norway) interfaced with a $2.5-3.5-\mathrm{MHz}$ phased-array probe. With the individuals in partial left decubitus and breathing normally, she obtained images, together with a simultaneous ECG signal, from the parasternal long and short axes and from the apical four and two-chamber long-axis views. All recordings included at least five cardiac cycles and were digitally stored for off-line analysis. M-mode echocardiograms of the left ventricle were recorded from the parasternal long-axis view under control of the twodimensional image. The ultrasound beam was positioned just below the mitral valve at the level of the posterior chordae tendineae.

To record LV outflow tract velocities from the apical window, the observer positioned the Doppler sample volume at the LV outflow. To record mitral flow velocities from the apical window, the observer positioned the Doppler sample volume at the mitral valve tips. Using tissue Doppler imaging (TDI), she recorded low-velocity, high-intensity myocardial signals at a high frame rate ( $>190$ FPS), while adjusting the imaging angle to ensure a parallel alignment of the ultrasound beam with the myocardial segment of interest. From the apical window, the sonographer placed a 5-mm Doppler sample at the septal, lateral, inferior, and posterior sites of the mitral annulus. The Nyquist limit was set as low as possible, avoiding aliasing.

\section{Off-line analysis}

The sonographer analyzed recorded images off-line, averaging three heart cycles for statistical analysis, using a workstation running the EchoPac software package, version 4.0.4 (GE Vingmed). The $\mathrm{LV}$ internal diameter and interventricular septal and posterior wall thickness were measured at end diastole from two-dimensionalguided M-mode tracings, as described in the American Society of Echocardiography guideline [9]. End-diastolic $\mathrm{LV}$ dimensions were used to calculate $\mathrm{LV}$ mass by an anatomically validated formula. RWT was calculated as the ratio of (interventricular septum + posterior wall)/LV internal diameter at end diastole. $\mathrm{LV}$ concentric remodelling was defined as RWT exceeding 0.43. LV endsystolic and end-diastolic volumes were calculated with the use of Teicholtz's method. Ejection fraction was calculated as the ratio of (end-diastolic volume-endsystolic volume)/LV end-diastolic volume. Intraobserver reproducibility was $2.2 \%$ for $\mathrm{LV}$ internal end-diastolic diameter, $4.6 \%$ for $\mathrm{LV}$ wall thickness, and $4.3 \%$ for $\mathrm{LV}$ mass. SV was calculated from the pulsed-wave Doppler velocity profile and the cross-sectional area at the $\mathrm{LV}$ outflow tract. Cardiac index $(C I)$ was calculated as the ratio of $(\mathrm{SV} \times \mathrm{HR}) /$ body surface area [body weight ${ }^{0.425}$ (in $\mathrm{kg}) \times$ body height ${ }^{0.725}($ in $\left.\mathrm{cm}) \times 0.007184\right]$. Total peripheral resistance index was assessed as the ratio of mean $\mathrm{BP} \times 80 / C I$.

From the transmitral flow signal, the observer measured peak early diastolic velocity $(E)$, peak late diastolic velocity $(A)$, and the $E / A$ ratio. From the TDI recordings, we determined peak early $\left(E_{\mathrm{a}}\right)$ and peak late $\left(A_{\mathrm{a}}\right)$ diastolic mitral annular velocities, and the $E_{\mathrm{a}} / A_{\mathrm{a}}$ ratio at the four acquisition sites (septal, lateral, inferior, and posterior). As described elsewhere [10], we extracted longitudinal strain 
curves off-line from colour myocardial Doppler images, using dedicated Software Package for Echocardiographic Quantification LEuven (SPEQLE) (version 4.6.2). We positioned the sampling volumes $(10 \mathrm{~mm})$ in the inferior and inferolateral walls at the level of the posterior chordae tendineae. To compute end-systolic longitudinal deformation, we averaged three consecutive cycles. Because there were no differences between the inferolateral and inferior walls in longitudinal strain, for statistical analysis we averaged these measurements and used their absolute values.

\section{Biochemical measurements}

On the day of the echocardiographic examination, after the individuals had rested in the supine position for at least $45 \mathrm{~min}$, venous blood samples were collected into EDTA tubes. After centrifuging, the plasma was separated, aliquoted, and stored at $-70^{\circ} \mathrm{C}$.

Endogenous ouabain was extracted from plasma and measured using a specific radioimmunoassay (RIA) as described [11]. Briefly, plasma samples were mixed with one volume of $0.1 \%$ trifluoroacetic acid in water and centrifuged at $3000 \mathrm{~g}$ for $30 \mathrm{~min}$ at $4^{\circ} \mathrm{C}$. The supernatants were passed, under vacuum, over prewashed C18 columns. Following a wash cycle involving water and then $2.5 \%$ acetonitrile, endogenous ouabain was eluted with $25 \%$ acetonitrile. The eluate was dried under vacuum. The extracts were reconstituted in RIA buffer, incubated at room temperature for $15 \mathrm{~h}$ in the presence of $3 \mathrm{H}$ ouabain and a rabbit polyclonal antiouabain antiserum. The incubation was interrupted by addition of stop solution and the rapid separation of bound from freelabelled ouabain by filtration over glass fiber filters. Trapped counts were determined by scintillation counting. The assay used a highly specific ouabain antiserum with low cross-reactivity for digoxin $(\sim 0.42 \%)$, spironolactone $(<0.01 \%)$, canrenone $(<0.01 \%)$, and canrenoate $(0.07 \%)$ but has no measurable interaction with any of the antihypertensive medications used by the patients [12].

The N-terminal portion of pro-B-type natriuretic peptide (NT-proBNP) was measured in plasma samples by a competitive enzyme immunoassay (EIA) for research use (Biomedica Gruppe, Vienna, Austria). The standard range provided by the manufacturer of the EIA is from zero to $1000 \mathrm{pmol} / \mathrm{l}$ (median $208 \mathrm{pmol} / \mathrm{l}$, 95th percentile $300 \mathrm{pmol} / \mathrm{l})$.

The participants also collected a timed 24-h urine sample in a wide-neck plastic container for the measurement of sodium, potassium, creatinine, and aldosterone. Urinary aldosterone concentration was measured by commercial RIA (DSL-8600 Active; Diagnostic Systems Laboratories Inc., Webster, Texas, USA). Electrolytes in urine and plasma were determined by flame photometry.

\section{Other measurements}

At the examination centre, trained study nurses administered a questionnaire to collect detailed information on each patient's medical history, smoking and drinking habits, and intake of medications. Hypertension was defined as a $\mathrm{BP}$ of at least $140 \mathrm{mmHg} \mathrm{SBP}$ or $90 \mathrm{mmHg}$ DBP (average of five consecutive readings at the examination centre) or as the use of antihypertensive drugs. Body mass index (BMI) was weight in kilograms divided by the square of height in meters.

\section{Statistical methods}

For database management and statistical analysis, we used SAS software, version 9.1 (SAS Institute). We normalized the distributions of plasma endogenous ouabain, NT-proBNP, and the urinary aldosterone excretion by a logarithmic transformation. We compared means and proportions using the large sample z-test and Fisher's exact test, respectively. Our statistical methods also included single and multiple linear regressions. We included in our models covariables with known physiological relevance for $L V$ structure and function $[10,13,14]$. We applied a generalization of the standard linear model, as implemented in the PROG MIXED procedure of the SAS package, to investigate the associations between the echocardiographic measurements and explanatory variables, while accounting for relatedness amongst study participants and adjusting for covariables. We expressed multivariable-adjusted effect sizes for 1-SD increase in the explanatory variables.

\section{Results \\ Characteristics of participants and endogenous ouabain distribution}

The 536 participants included $272(50.7 \%)$ women and $205(38.2 \%)$ hypertensive patients, of whom $116(21.6 \%)$ were on antihypertensive drug treatment. Twenty-seven women $(9.9 \%)$ used oral contraceptives and seven (2.3\%) took hormonal replacement therapy. The distribution of plasma endogenous ouabain departed from normality and was positively skewed $(P<0.0001)$ with a coefficient of skewness amounting to 5.02. The geometric mean plasma endogenous ouabain was $95.5 \mathrm{pmol} / 1$ [interquartile range (IQR) 79.4-120.2 pmol/l]. Table 1 shows the clinical characteristics of the study participants by quartiles of plasma endogenous ouabain. With higher plasma endogenous ouabain, there was an increase in SBP $(P=0.014$, Table 1$)$. The prevalence of hypertensive patients also increased with higher endogenous ouabain (Table 1). There were no significant differences amongst the endogenous ouabain quartiles in age, anthropometric characteristics, DBP, HR, and biochemical variables (Table 1).

As expected, in univariate regression analysis $(r=0.13$, $P=0.0028$, Fig. 1) and in an analysis adjusted for sex, age, age squared, BMI, antihypertensive treatment, and use of 
Table 1 Clinical characteristics of participants by endogenous ouabain quartiles

\begin{tabular}{|c|c|c|c|c|c|}
\hline Characteristic & $\begin{array}{c}\text { Low } \\
(n=134)\end{array}$ & $\begin{array}{l}\text { Medium-low } \\
\quad(n=134)\end{array}$ & $\begin{array}{l}\text { Medium-high } \\
\quad(n=134)\end{array}$ & $\begin{array}{c}\text { High } \\
(n=134)\end{array}$ & $P$ \\
\hline Limits (pmol/l) & $<79.4$ & $79.4-95.4$ & $95.5-120.2$ & $>120.2$ & - \\
\hline \multicolumn{6}{|l|}{ Anthropometrics } \\
\hline Age (years) & $50.3 \pm 14.0$ & $50.3 \pm 15.1$ & $50.6 \pm 14.9$ & $53.6 \pm 14.9$ & 0.19 \\
\hline $\mathrm{BMI}\left(\mathrm{kg} / \mathrm{m}^{2}\right)$ & $26.3 \pm 3.6$ & $26.3 \pm 4.7$ & $26.0 \pm 3.7$ & $26.1 \pm 3.9$ & 0.92 \\
\hline Sex, women (\%) & $69(51.5)$ & $72(53.7)$ & $67(50.0)$ & $64(47.8)$ & 0.44 \\
\hline $\mathrm{SBP}(\mathrm{mmHg})$ & $126.7 \pm 16.1$ & $127.8 \pm 16.2$ & $127.8 \pm 16.3$ & $132.8 \pm 18.5$ & 0.014 \\
\hline $\mathrm{DBP}(\mathrm{mmHg})$ & $78.9 \pm 8.2$ & $79.0 \pm 8.2$ & $79.8 \pm 9.2$ & $80.4 \pm 10.8$ & 0.45 \\
\hline HR (beats/min) & $60.8 \pm 9.4$ & $61.4 \pm 9.3$ & $60.6 \pm 8.9$ & $60.2 \pm 9.5$ & 0.78 \\
\hline \multicolumn{6}{|l|}{ Questionnaire data } \\
\hline Current smoking, $n(\%)$ & 32 (23.9) & $29(21.6)$ & $28(20.9)$ & $28(20.9)$ & 0.54 \\
\hline Drinking alcohol, $n(\%)$ & $57(42.5)$ & $57(42.5)$ & $60(44.8)$ & $57(42.5)$ & 0.91 \\
\hline Hypertensive, $n(\%)$ & $41(30.6)$ & $44(32.8)$ & $57(42.5)$ & $63(47.0)$ & 0.002 \\
\hline Treated for hypertension, $n(\%)$ & $22(16.4)$ & $29(21.6)$ & $34(25.4)$ & $31(23.1)$ & 0.13 \\
\hline \multicolumn{6}{|l|}{ Biochemical data } \\
\hline Total cholesterol $(\mathrm{mmol} / \mathrm{l})$ & $5.28 \pm 1.02$ & $5.28 \pm 0.99$ & $5.32 \pm 1.01$ & $5.31 \pm 1.03$ & 0.98 \\
\hline Serum $\mathrm{Na}+(\mathrm{mmol} / \mathrm{l})$ & $140.2 \pm 1.94$ & $140.1 \pm 1.66$ & $140.3 \pm 1.91$ & $140.1 \pm 1.72$ & 0.77 \\
\hline Serum K+ (mmol/l) & $4.45 \pm 0.35$ & $4.39 \pm 0.33$ & $4.46 \pm 0.41$ & $4.38 \pm 0.45$ & 0.19 \\
\hline NT-proBNP (pmol/l) & 209 (158 to 288$)$ & 219 (166 to 309$)$ & 219 (162 to 302$)$ & 219 (166 to 288$)$ & 0.89 \\
\hline Urinary volume (I/day) & $1.78 \pm 0.66$ & $1.82 \pm 0.83$ & $1.76 \pm 0.68$ & $1.85 \pm 0.80$ & 0.77 \\
\hline Creatinine excretion (mmol/day) & $149 \pm 60$ & $198 \pm 73$ & $149 \pm 60$ & $198 \pm 73$ & \\
\hline 24-h urinary $\mathrm{Na}+(\mathrm{mmol} / \mathrm{day})$ & $178 \pm 76$ & $159 \pm 65$ & $178 \pm 77$ & $173 \pm 70$ & 0.10 \\
\hline 24-h urinary $\mathrm{K}+(\mathrm{mmol} / \mathrm{day})$ & $72 \pm 30$ & $70 \pm 26$ & $76 \pm 26$ & $75 \pm 26$ & 0.30 \\
\hline Urinary $\mathrm{Na}+/ \mathrm{K}+$ ratio & $2.56 \pm 0.93$ & $2.40 \pm 0.92$ & $2.47 \pm 0.98$ & $2.36 \pm 0.76$ & 0.29 \\
\hline 24-h aldosterone $(\mathrm{mmol} /$ day $)$ & 21.4 (15.1 to 31.6$)$ & 20.4 (14.8 to 30.9$)$ & $22.9(14.8$ to 31.6$)$ & $22.4(14.1$ to 33.1$)$ & 0.96 \\
\hline
\end{tabular}

Values are mean $( \pm \mathrm{SD})$, geometric mean (IQR), or number of individuals $(\%)$. $P$ values are for differences across quartiles. HR, heart rate; IQR, interquartile range.

Fig. 1
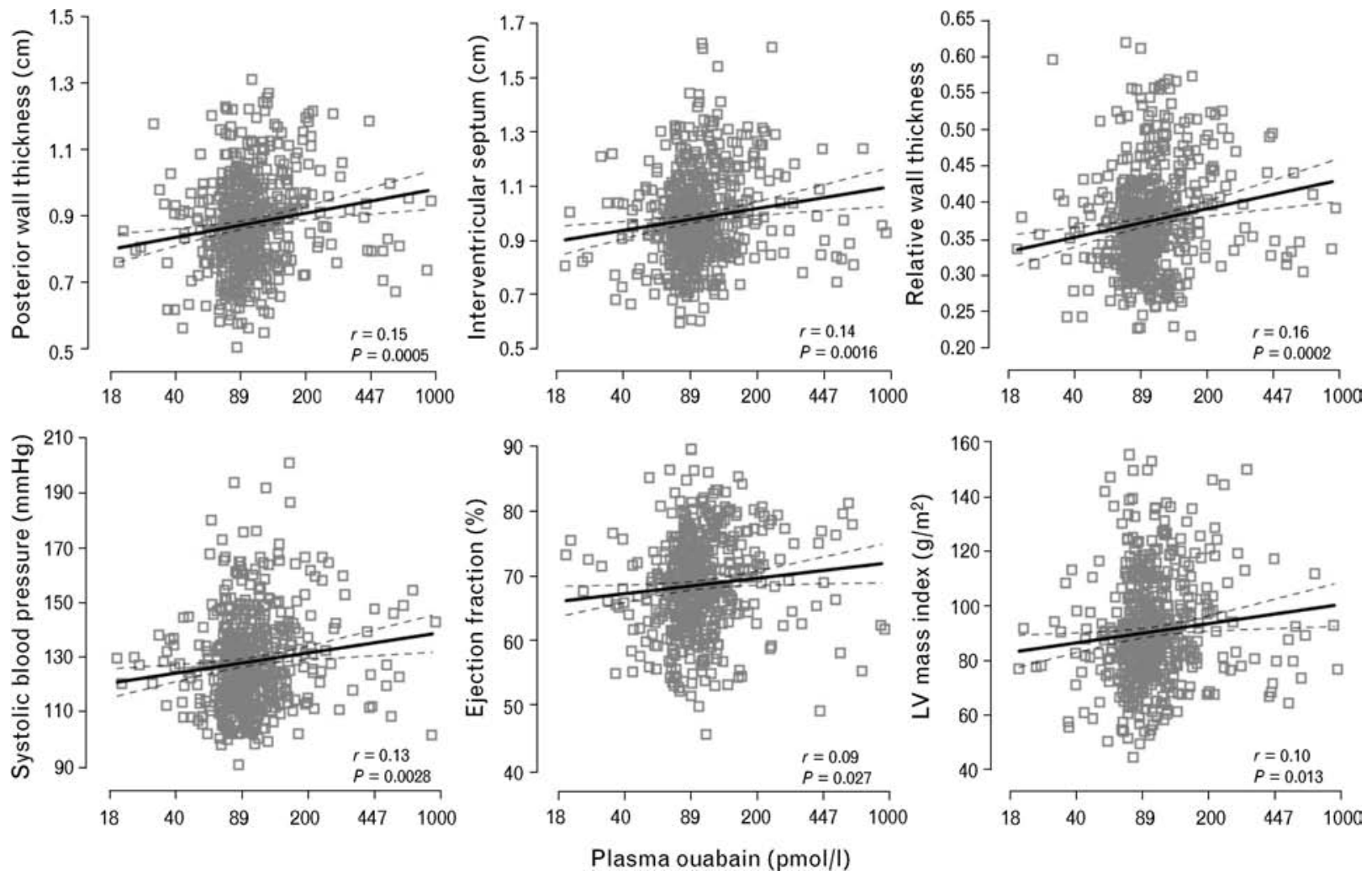

Scatter plots of the left ventricular wall thickness, relative wall thickness, left ventricular mass index, ejection fraction, and SBP versus plasma endogenous ouabain. The full and dotted lines represent the regression line and the $95 \%$ confidence interval, respectively. 
Table 2 Echocardiographic characteristics of participants by endogenous ouabain quartiles

\begin{tabular}{|c|c|c|c|c|c|}
\hline Characteristic & $\begin{array}{c}\text { Low } \\
(n=134)\end{array}$ & $\begin{array}{l}\text { Medium-low } \\
\quad(n=134)\end{array}$ & $\begin{array}{l}\text { Medium-high } \\
\quad(n=134)\end{array}$ & $\begin{array}{c}\text { High } \\
(n=134)\end{array}$ & $P$ \\
\hline Limits $(p m o l / l)$ & $<79.4$ & $79.4-95.4$ & $95.5-120.2$ & $>120.2$ & - \\
\hline \multicolumn{6}{|l|}{ Conventional echocardiography } \\
\hline Left atrial diameter (mm) & $39.4 \pm 5.2$ & $39.2 \pm 5.6$ & $38.8 \pm 5.1$ & $39.6 \pm 5.0$ & 0.63 \\
\hline LV internal diastolic diameter (mm) & $50.3 \pm 4.8$ & $50.4 \pm 4.5$ & $50.0 \pm 4.5$ & $49.8 \pm 5.1$ & 0.74 \\
\hline LV internal systolic diameter $(\mathrm{mm})$ & $31.4 \pm 4.3$ & $30.5 \pm 4.0$ & $30.5 \pm 4.5$ & $29.8 \pm 5.4$ & 0.044 \\
\hline Interventricular septum (mm) & $9.6 \pm 1.5$ & $9.6 \pm 1.6$ & $10.0 \pm 1.9$ & $10.3 \pm 1.8$ & 0.002 \\
\hline Posterior wall (mm) & $8.6 \pm 1.4$ & $8.5 \pm 1.3$ & $8.8 \pm 1.4$ & $9.2 \pm 1.5$ & 0.0001 \\
\hline RWT & $0.36 \pm 0.063$ & $0.36 \pm 0.063$ & $0.38 \pm 0.079$ & $0.40 \pm 0.077$ & 0.0002 \\
\hline LV mass $(\mathrm{g})$ & $165 \pm 46$ & $165 \pm 43$ & $170 \pm 43$ & $177 \pm 45$ & 0.07 \\
\hline LV mass index $\left(\mathrm{g} / \mathrm{m}^{2}\right)$ & $88.4 \pm 20.5$ & $88.3 \pm 18.6$ & $91.8 \pm 19.3$ & $94.8 \pm 19.2$ & 0.016 \\
\hline LV hypertrophy, $n(\%)$ & $10(7.5)$ & $7(5.2)$ & $15(11.2)$ & $17(12.7)$ & 0.05 \\
\hline LV concentric remodelling, $n(\%)$ & $14(10.4)$ & $13(9.7)$ & $30(22.4)$ & $44(32.8)$ & $<0.0001$ \\
\hline Ejection fraction (\%) & $66.8 \pm 7.0$ & $69.3 \pm 6.7$ & $68.6 \pm 7.4$ & $70.1 \pm 8.4$ & 0.002 \\
\hline \multicolumn{6}{|l|}{ Doppler echocardiography } \\
\hline SV $(\mathrm{ml})$ & $83.5 \pm 15.7$ & $83.9 \pm 16.6$ & $83.0 \pm 15.9$ & $86.2 \pm 19.6$ & 0.45 \\
\hline $\mathrm{Cl}\left(\mathrm{I} / \mathrm{min} / \mathrm{m}^{2}\right)$ & $2.72 \pm 0.49$ & $2.76 \pm 0.53$ & $2.72 \pm 0.54$ & $2.77 \pm 0.50$ & 0.75 \\
\hline Total peripheral resistance (dynes $* s * \mathrm{~cm}^{-5} * \mathrm{~m}^{2}$ ) & $2873 \pm 527$ & $2853 \pm 597$ & $2904 \pm 597$ & $2899 \pm 554$ & 0.87 \\
\hline Transmitral $E / A$ ratio & $1.27 \pm 0.52$ & $1.25 \pm 0.52$ & $1.26 \pm 0.52$ & $1.26 \pm 0.52$ & 0.99 \\
\hline TDI $E_{\mathrm{a}} / A_{\mathrm{a}}$ ratio & $1.22 \pm 0.52$ & $1.26 \pm 0.52$ & $1.24 \pm 0.52$ & $1.16 \pm 0.52$ & 0.53 \\
\hline$E / E_{\mathrm{a}}$ ratio & $6.73 \pm 0.52$ & $6.86 \pm 0.52$ & $6.93 \pm 0.52$ & $7.22 \pm 0.52$ & 0.18 \\
\hline Longitudinal strain (\%) & $23.1 \pm 3.47$ & $23.3 \pm 3.62$ & $22.9 \pm 4.06$ & $22.4 \pm 3.28$ & 0.31 \\
\hline
\end{tabular}

Values are mean ( $\pm \mathrm{SD}$ ), geometric mean (IQR range), or number of individuals (\%). $P$ values are for differences across quartiles. $C l$, cardiac index; IQR, interquartile range; LV, left ventricular; RWT, relative wall thickness; SV, stroke volume; TDI, tissue Doppler imaging.

oral contraceptives, there was a positive association between SBP and plasma endogenous ouabain. With adjustments applied, a 1-SD increase in plasma endogenous ouabain was associated with an increase in SBP by $1.59 \mathrm{mmHg}(P=0.009$, Table 3$)$.

\section{Association between LV phenotypes and plasma endogenous ouabain}

Table 2 shows the echocardiographic and hemodynamic data of the study population grouped according to plasma endogenous ouabain quartiles. In unadjusted analyses in which we treated the plasma endogenous ouabain as a continuous (Fig. 1) or categorical variable (Table 2), LV wall thickness, RWT, LV mass index, and ejection fraction increased with plasma endogenous ouabain level
$(P \leq 0.027)$, whereas LV systolic diameter decreased with plasma endogenous ouabain $(P=0.044$, Table 2$)$. There were no significant differences amongst the endogenous ouabain quartiles in SV, $C I$, total peripheral resistance, or variables reflecting diastolic function and $\mathrm{LV}$ longitudinal strain (Table 2).

In multivariable-adjusted analyses accounting for sex, age, BMI, SBP, and use of antihypertensive drugs, only $\mathrm{LV}$ wall thickness and RWT significantly increased with plasma endogenous ouabain (Table 3). For a 1-SD increment in plasma endogenous ouabain, $\mathrm{LV}$ posterior wall, the interventricular septum, and RWT increased by $0.138 \mathrm{~mm} \quad(P=0.003), 0.152 \mathrm{~mm} \quad(P=0.013)$, and $0.71 \times 10^{-2} \quad(P=0.008)$, respectively. $\mathrm{LV}$ concentric

Table 3 Adjusted LV traits and BP in relation to plasma endogenous ouabain in different age groups

\begin{tabular}{|c|c|c|c|c|c|c|c|c|}
\hline \multirow[b]{2}{*}{ Characteristic } & \multicolumn{2}{|l|}{ All individuals $(n=536)$} & \multicolumn{2}{|c|}{ Age $20-80$ years $(n=523)$} & \multicolumn{2}{|c|}{ Age $29-71$ years $(n=431)$} & \multicolumn{2}{|c|}{ Age $42-62$ years $(n=273)$} \\
\hline & Estimate $(95 \% \mathrm{Cl})$ & $P$ & Estimate $(95 \% \mathrm{Cl})$ & $P$ & Estimate $(95 \% \mathrm{Cl})$ & $P$ & Estimate $(95 \% \mathrm{Cl})$ & $P$ \\
\hline Posterior wall (mm) & $0.138(0.046$ to 0.229$)$ & 0.003 & 0.140 (0.046 to 0.233$)$ & 0.004 & $0.129(0.028$ to 0.230$)$ & 0.01 & $0.133(0.006$ to 0.260$)$ & 0.04 \\
\hline $\begin{array}{l}\text { Interventricular } \\
\text { septum (mm) }\end{array}$ & $0.152(0.032$ to 0.273$)$ & 0.013 & $0.154(0.032$ to 0.275$)$ & 0.013 & $0.182(0.051$ to 0.313$)$ & 0.006 & $0.233(0.073$ to 0.393$)$ & 0.005 \\
\hline $\begin{array}{l}\text { LV diastolic } \\
\quad \text { diameter }(\mathrm{mm})\end{array}$ & $-0.227(-0.567$ to 0.110$)$ & 0.18 & $-0.256(-0.601$ to 0.090$)$ & 0.15 & $-0.338(-0.703$ to 0.028$)$ & 0.07 & $-0.609(-1.05$ to -0.175$)$ & 0.06 \\
\hline RWT $\left(\times 10^{-2}\right)$ & $0.71(0.19$ to 1.23$)$ & 0.008 & $0.75(0.22$ to 1.28$)$ & 0.006 & $0.86(0.29$ to 1.43$)$ & 0.003 & $1.21(0.53$ to 1.90$)$ & 0.0006 \\
\hline LV mass $(\mathrm{g})$ & $2.07(-0.59$ to 4.73$)$ & 0.12 & $1.99(-0.73$ to 4.71$)$ & 0.15 & $1.97(-0.98$ to 4.93$)$ & 0.19 & $0.80(-2.88$ to 4.48$)$ & 0.67 \\
\hline LV mass index $\left(\mathrm{g} / \mathrm{m}^{2}\right)$ & $1.01(-0.40$ to 2.43$)$ & 0.16 & $0.96(-0.48$ to 2.41$)$ & 0.19 & $0.89(-0.67$ to 2.46$)$ & 0.26 & $0.22(-1.58$ to 2.41$)$ & 0.68 \\
\hline Ejection fraction (\%) & $0.38(-0.23$ to 1.38$)$ & 0.22 & $0.54(-0.07$ to 1.16$)$ & 0.08 & $0.90(0.28$ to 1.52$)$ & 0.005 & $1.14(0.34$ to 1.94$)$ & 0.005 \\
\hline Longitudinal strain (\%) & $-0.31(-0.65$ to 0.04$)$ & 0.08 & $-0.36(-0.72$ to -0.02$)$ & 0.04 & $-0.48(-0.85$ to -0.11$)$ & 0.011 & $-0.57(-1.05$ to -0.08$)$ & 0.022 \\
\hline $\mathrm{SBP}(\mathrm{mmHg})$ & 1.59 (0.39 to 2.80$)$ & 0.009 & $1.62(0.39$ to 2.85$)$ & 0.010 & $1.68(0.33$ to 3.03$)$ & 0.015 & $1.22(-0.45$ to 2.89$)$ & 0.15 \\
\hline $\mathrm{DBP}(\mathrm{mmHg})$ & $0.46(-0.23$ to 1.16$)$ & 0.19 & $0.46(-0.25$ to 1.17$)$ & 0.20 & $0.43(-0.34$ to 1.21$)$ & 0.27 & $-0.02(-1.00$ to 0.96$)$ & 0.97 \\
\hline
\end{tabular}

Effect sizes are expressed for a 1-SD increase in plasma endogenous ouabain (0.21 on the logarithmic scale). BP, blood pressure; Cl, confidence interval; $\mathrm{HR}$, heart rate; LV, left ventricular; RWT, relative wall thickness. LV traits were adjusted for sex, age, BMI (not applicable to LV mass index), SBP, and antihypertensive drug treatment. Ejection fraction was adjusted for sex, age, BMI, and HR. Longitudinal strain was adjusted for sex, age, and waist-to-hip ratio. BP was adjusted for sex, age, age squared, $\mathrm{BMI}$, and use of antihypertensive drug treatment or oral contraceptives. 
Table 4 Adjusted LV traits and BP in relation to plasma endogenous ouabain by sodium excretion

\begin{tabular}{|c|c|c|c|c|}
\hline \multirow[b]{2}{*}{ Characteristic } & \multicolumn{2}{|c|}{$\mathrm{Na}<161 \mathrm{mmol} / 24 \mathrm{~h}(n=265)$} & \multicolumn{2}{|c|}{$\mathrm{Na} \geq 161 \mathrm{mmol} / 24 \mathrm{~h}(n=267)$} \\
\hline & Estimate $(95 \% \mathrm{Cl})$ & $P$ & Estimate $(95 \% \mathrm{Cl})$ & $P$ \\
\hline Posterior wall (mm) & $0.103(-0.016$ to 0.223$)$ & 0.09 & $0.203(0.058$ to 0.350$)$ & 0.006 \\
\hline Interventricular septum (mm) & $0.089(-0.068$ to 0.246$)$ & 0.26 & $0.227(0.039$ to 0.414$)$ & 0.018 \\
\hline LV diastolic diameter $(\mathrm{mm})$ & $-0.035(-0.491$ to 0.422$)$ & 0.88 & $-0.542(-1.06$ to -0.026$)$ & 0.040 \\
\hline RWT $\left(x 10^{-2}\right)$ & $0.32(-0.36$ to 1.01$)$ & 0.35 & $1.22(0.43$ to 2.02$)$ & 0.003 \\
\hline LV mass $(\mathrm{g})$ & $1.71(-1.55$ to 4.96$)$ & 0.30 & $2.10(-2.21$ to 6.41$)$ & 0.34 \\
\hline LV mass index $\left(\mathrm{g} / \mathrm{m}^{2}\right)$ & $0.86(-0.95$ to 2.67$)$ & 0.35 & $1.20(-1.05$ to 3.45$)$ & 0.29 \\
\hline Ejection fraction (\%) & $0.23(-0.65$ to 1.12$)$ & 0.60 & $0.41(-0.41$ to 1.24$)$ & 0.32 \\
\hline Longitudinal strain (\%) & $-0.10(-0.58$ to 0.38$)$ & 0.69 & $-0.50(-1.00$ to -0.005$)$ & 0.048 \\
\hline $\mathrm{SBP}(\mathrm{mmHg})$ & $1.10(-0.64$ to 2.84$)$ & 0.21 & $2.25(0.55$ to 3.97$)$ & 0.010 \\
\hline $\mathrm{DBP}(\mathrm{mmHg})$ & $0.002(-0.95$ to 0.96$)$ & 0.99 & $1.07(0.036$ to 2.10$)$ & 0.043 \\
\hline
\end{tabular}

Effect sizes are expressed for a 1-SD increase in plasma endogenous ouabain ( 0.21 on the logarithmic scale). BP, blood pressure; Cl, confidence interval; $\mathrm{HR}$, heart rate; LV, left ventricular; RWT, relative wall thickness. LV traits were adjusted for sex, age, BMI (not applicable to LV mass index), SBP, and antihypertensive drug treatment. Ejection fraction was adjusted for sex, age, BMI, and HR. Longitudinal strain was adjusted for sex, age, and waist-to-hip ratio. BP was adjusted for sex, age, age squared, $\mathrm{BMI}$, and use of antihypertensive drug treatment or oral contraceptives.

remodelling was more prevalent with higher plasma endogenous ouabain $(P<0.0001$, Table 2$)$, even after adjustment for covariables.

\section{Sensitivity analyses}

In sensitivity analyses, we narrowed the age range, first by excluding 13 participants younger than 20 or older than 80 years (1st-99th percentile interval), and next by only including in our analyses participants with an age range corresponding to the $10-90$ th percentile interval (29-71 years, $n=431)$ or to the IQR (42-62 years, $n=273$ ). As shown in Table 3 , the results of these sensitivity analyses, adjusted for covariables, were confirmatory for LV wall thickness, RWT, and SBP. Moreover, by narrowing the age range we noticed that a 1-SD increase in plasma endogenous ouabain was associated with opposite trends in ejection fraction $(+0.90 \%$, $P=0.005)$ and $L V$ systolic longitudinal strain $(-0.48 \%$, $P=0.011)$. Similarly, we repeated our analyses after exclusion of individuals on antihypertensive drugs. In 420 untreated individuals, our findings remained consistent. SBP, LV wall thickness, and RWT increased with plasma endogenous ouabain $(P \leq 0.02)$.

In further sensitivity analyses, we treated the urinary sodium excretion as a continuous variable or a variable dichotomized by the population median $(160 \mathrm{mmol} / 24 \mathrm{~h})$. In individuals whose urinary sodium excretion was below median, the aforementioned associations of plasma endogenous ouabain with $\mathrm{BP}$ and the $\mathrm{LV}$ traits were in the same direction, but did not reach statistical significance $(P \geq 0.09$, Table 4$)$. In contrast, in participants with a sodium excretion above median, these associations reached a higher level of statistical significance (Table 4). We did not observe significant interaction between plasma endogenous ouabain and urinary sodium excretion in relation to any trait under study $(P \geq 0.09)$.

\section{Discussion}

The key finding was that, with adjustments applied, SBP and $L V$ wall thickness increased with plasma endogenous ouabain. The significant positive association of RWT with plasma endogenous ouabain rested on increased LV wall thickness and a slightly decreased LV internal end-diastolic diameter. Our findings are in line with previous studies in selected groups of hypertensive patients. In 92 never-treated hypertensive patients, Pierdomenico $e t$ al. [5] noticed that plasma endogenous ouabain was significantly higher in patients with concentric remodelling than in those with normal geometry or concentric hypertrophy. In 128 untreated hypertensive patients, Manunta et al. [6] found that LV mass, SV, and RWT increased and HR decreased with higher circulating endogenous ouabain level. In this study, nearly $50 \%$ of patients with uncomplicated essential hypertension had elevated plasma endogenous ouabain compared with normotensive individuals.

In the current study, sensitivity analyses in untreated individuals or in a limited age range group provided confirmatory results. Moreover, by controlling the age range, and thereby decreasing the variability in $\mathrm{LV}$ systolic function, we observed that higher plasma levels of endogenous ouabain were associated with an increased ejection fraction and a decreased LV systolic longitudinal deformation. The effect of endogenous ouabain on LV systolic function might be explained by the observed association between RWT and plasma endogenous ouabain. Indeed, in our previous report [10], longitudinal end-systolic strain significantly and independently decreased with age and RWT, whereas ejection fraction increased with age and RWT.

In the current study, the associations of plasma endogenous ouabain with $\mathrm{LV}$ traits and $\mathrm{BP}$ were tighter at higher sodium excretion irrespective of whether sodium excretion was treated as a continuous variable or dichotomized by median. At variance with a previous report [15], we did not find significant interaction between sodium excretion and circulating endogenous ouabain in relation to BP. In the previous study [15], plasma endogenous ouabain apparently behaved as a BP-modulating factor. 
In individuals with plasma endogenous ouabain values below the median (140 pmol/l), SBP and DBP increased by 2.2 and $1.4 \mathrm{mmHg}$, respectively, for each $50 \mathrm{mmol} / 24 \mathrm{~h}$ increment in urinary sodium excretion $(P<0.01)$. No association between BP and urinary sodium excretion was found when plasma endogenous ouabain exceeded the median. However, in the previous study [15], conditions of measurement were different. Blood samples were obtained in the sitting position, and $\mathrm{BP}$ was measured at individuals' homes. In never-treated hypertensive patients [16] and in healthy individuals [17], acute interventions that promoted loss of body sodium (administration of diuretic) raised circulating endogenous ouabain. To our knowledge, no previous studies investigated the interaction between plasma endogenous ouabain and sodium excretion in relation to the structural and functional properties of the left ventricle.

Experimental studies suggested that endogenous ouabain originates from the adrenocortical gland and possibly from the hypothalamus. Endogenous ouabain has been isolated from bovine adrenals and hypothalamus [18,19]. Cultured human and bovine adrenocortical cells secrete endogenous ouabain into the culture fluid [20]. In conscious catheterized dogs, the endogenous ouabain content was approximately 5-6-fold higher in adrenal venous blood than in arterial blood [21]. With prolonged adrenalectomy and cortisone replacement in rats, the plasma concentration of endogenous ouabain was not measurable [22].

The mechanisms underlying the present association of LV geometry with plasma endogenous ouabain remain to be elucidated. Endogenous ouabain circulates in plasma in subnanomolar concentrations, which might be too low to inhibit $\mathrm{Na}+, \mathrm{K}+-\mathrm{ATP}$ ase [23]. In-vitro studies demonstrated that ouabain at very low concentrations $\left(10^{-10} \mathrm{~mol} / \mathrm{l}\right)$ promoted cell growth via activation of the ERK1/2 pathway in rat cardiomyoctyes [24] and in proximal tubular cells [25], as well as in human umbilical vein smooth muscle cells [26]. Furthermore, Ferrandi et al. [4] induced cardiac growth in rats by infusing ouabain at a rate of $15 \mu \mathrm{g} / \mathrm{kg} / \mathrm{day}$ for 18 weeks, which doubled the circulating ouabain level from 0.3 to $0.7 \mathrm{nmol} / \mathrm{l}$ and increased BP by $20 \mathrm{mmHg}$ and the weight of the left ventricle by $11 \%$. These in-vivo effects are associated with significant enrichment of $\alpha 1, \beta 1$, ya $\mathrm{Na}+, \mathrm{K}+$-ATPase subunits together with $\mathrm{Src}$ and EGFr in isolated renal caveolae membranes, and with activation of ERK1/2 [4]. On the contrary, Rossoni et al. [27] showed that treatment of rats with a higher concentration of ouabain $(8 \mu \mathrm{g} /$ day $)$ for a shorter period (5 weeks) induced hypertension without LV hypertrophy or impaired function of the sarcoplasmic reticulum. These authors also showed positive inotropic and lusitropic effects on the hearts of ouabain-treated rats, which were associated with an increment in the activity of myosin ATPase and in the expression of the catalytic subunit of the $\mathrm{Na}+, \mathrm{K}+$-ATPase. More recently Jiang et al. [28] described ouabain-induced cardiac hypertrophy in rats before the BP started to increase.

Since the original report published in 1991 [29], many laboratories, albeit not all, were able to detect endogenous ouabain in tissues and isolate it from tissues and plasma, using a variety of immunoassays (RIA, enzyme-linked immunosorbent assay, EIA, and dissociation-enhanced lanthanide fluorescent immunoassay). Comparable with hormones circulating in plasma at subnanomolar concentrations, such as NT-proBNP, the normal range of endogenous ouabain varied between laboratories [30,31]. Variability in reported plasma endogenous ouabain levels might be explained by differences in the immunoassay radioactive label, the sensitivity of the ouabain antibodies, and cross-reactivity with other glycosides or steroid hormones with similar polarity [30,31]. In our population study, we used a RIA, which was carefully standardized as previously reported [11]. In the current study, the geometric mean concentration of plasma endogenous ouabain was $95.5 \mathrm{pmol} / \mathrm{l}$, which is lower than reported previously in our Flemish population ( $140 \mathrm{pmol} / \mathrm{l})$ using the same RIA [15]. Body position and prolonged rest in the supine position might explain the lower level. Indeed, in the present study, we collected plasma after the participants had rested lying for at least $45 \mathrm{~min}$. In humans and dogs, physical exercise raises the circulating endogenous ouabain level [32].

The present study must be interpreted within the context of its limitation. Variables reflecting LV structure and function are quantitative traits prone to measurement error. However, only one experienced observer performed all ultrasound examinations. We excluded patients with overt heart disease that change cardiac structure. Extensive studies have been performed to validate the RIA for plasma endogenous ouabain used in the current study [33]. Amongst 21 patients, a positive correlation $(P<0.001)$ has been observed between plasma endogenous ouabain measured by both HPLC-mass spectrometry and RIA (Ferrandi M, Hamlyn J, Manunta $\mathrm{P}$; unpublished observation).

\section{Conclusion}

Our population-based study suggested that endogenous ouabain might have a trophic effect on the myocardium, independent of BP and other covariables. Elevated circulating ouabain might be a factor that contributes to an increased risk of $\mathrm{LV}$ remodelling and hypertrophy amongst patients with essential hypertension. These findings need replication in other populations and patient cohorts as well as in longitudinal studies. Approximately one-third of essential hypertensive patients show an increased level of circulating ouabain, which is associated with renal and cardiac remodelling [31]. A new compound, rostafuroxin, which antagonizes the pathological molecular effects of endogenous ouabain, might open 
new possibilities for the therapy of hypertension and the related target organ damage [34].

\section{Acknowledgements}

Research included in the present study was partially funded by the European Union (grants IC15-CT980329-EPOGH, LSHM-CT-2006-037093 InGenious HyperCare, and HEALTH-2007-2.1.1-2 HyperGenes), the Fonds voor Wetenschappelijk Onderzoek Vlaanderen, Brussels, Belgium (grants G.0256.05 and G.0575.06), and the Katholieke Universiteit Leuven, Leuven, Belgium (grants OT/04/34 and OT/05/49).

The authors gratefully acknowledge the expert assistance of Sandra Covens, Linda Custers, Marie-Jeanne Jehoul, Hanne Truyens, Ya Zhu (Studies Coordinating Centre, Leuven, and Field Examination Centre, Eksel, Belgium).

\section{References}

1 Hamlyn JM, Ringel R, Schaeffer J, Levinson PD, Hamilton BP, Kowarski AA, Blaustein MP. A circulating inhibitor of $\left(\mathrm{Na}^{+}+\mathrm{K}^{+}\right)$ATPase associated with essential hypertension. Nature 1982; 300:650-652.

2 Schoner W. Endogenous cardiac glycosides, a new class of steroid hormones. Eur J Biochem 2002; 269:2440-2448.

3 Bova S, Blaustein MP, Ludens JH, Harris DW, DuCharme DW, Hamlyn JM. Effects of an endogenous ouabain like compound on heart and aorta. Hypertension 1991; 17:944-950.

4 Ferrandi M, Molinari I, Barassi P, Minotti E, Bianchi G, Ferrari P. Organ hypertrophic signaling within caveolae membrane subdomains triggered by ouabain and antagonized by PST2238. J Biol Chem 2004; 279:3330633314.

5 Pierdomenico SD, Bucci A, Manunta P, Rivera R, Ferrandi M, Hamlyn JM, et al. Endogenous ouabain and hemodynamic and left ventricular geometric patterns in essential hypertension. Am J Hypertens $2001 ; 14: 44-50$.

6 Manunta P, Stella P, Rivera R, Ciurlino D, Cusi D, Ferrandi M, et al. Left ventricular mass, stroke volume, and ouabain-like factor in essential hypertension. Hypertension 1999; 34:450-456.

7 Staessen JA, Wang JG, Brand E, Barlassina C, Birkenhäger WH, Herrmann $\mathrm{SM}$, et al. Effects of three candidate genes on prevalence and incidence of hypertension in a Caucasian population. J Hypertens 2001 ; 19:13491358.

8 Li Y, Zagato L, Kuznetsova T, Tripodi G, Zerbini G, Richart T, et al. Angiotensin-converting enzyme I/D and $\alpha$-adducin Gly460Trp polymorphisms. From angiotensin-converting enzyme activity to cardiovascular outcome. Hypertension 2007; 49:1291-1297.

9 Gottdiener JS, Bednarz J, Devereux R, Gardin J, Klein A, Manning WJ, et al. American Society of Echocardiography recommendations for use of echocardiography in clinical trials. A report from the American Society of Echocardiography's Guidelines and Standard Committee and the Task Force on Echocardiography in Clinical Trials. J Am Soc Echocardiogr $2004 ; 17: 1086-1119$.

10 Kuznetsova T, Herbots L, Richart T, D'hooge J, Thijs L, Fagard R, et al. Left ventricular strain and strain rate in a general population. Eur Heart J 2008; 29:2014-2023.

11 Ferrandi M, Manunta P, Balzan S, Hamlyn JM, Bianchi G, Ferrari P. Ouabain-like factor quantification in mammalian tissues and plasma. Comparison of two independent assays. Hypertension 1997; 30:886896.

12 Harris DW, Clark MA, Fisher JF, Hamlyn JM, Kolbasa KP, Ludens JH, Du Charme DW. Development of an immunoassay for endogenous digitalis like factor. Hypertension 1991; 17:936-943.

13 Kuznetsova T, Staessen JA, Thijs L, Kunath C, Olszanecka A, Ryabikov A, et al., for the European Project on Genes in Hypertension (EPOGH) Investigators. Left ventricular mass in relation to genetic variation in angiotensin II receptors, renin system genes, and sodium excretion. Circulation 2004; 110:2644-2650.

14 Kuznetsova T, Citterio L, Herbots L, Delli Carpini S, Thijs L, Casamassima $\mathrm{N}$, et al. Effects of genetic variation in adducin on left ventricular diastolic function as assessed by tissue Doppler imaging in a Flemish population. J Hypertens 2008; 26:1229-1236.
15 Wang JG, Staessen JA, Messaggio E, Nawrot T, Fagard R, Hamlyn JM, et al. Salt, endogenous ouabain and blood pressure in the general population. J Hypertens 2003; 21:1475-1481.

16 Manunta P, Messaggio E, Ballabeni C, Sciarrone MT, Lanzani C, Ferrandi M, et al., for the Salt Sensitivity Group of the Italian Society of Hypertension. Plasma ouabain-like factor during acute and chronic changes in sodium balance in essential hypertension. Hypertension 2001; 38:198-203.

17 Manunta P, Hamilton BP, Hamlyn JM. Salt intake and depletion increase circulating levels of endogenous ouabain in normal men. Am J Physiol Regul Integr Comp Physiol 2006; 290:R553-R559.

18 Schneider R, Wray V, Nimtz M, Lehmann WD, Kirch U, Antolovic R, Schoner W. Bovine adrenals contain, in addition to ouabain, a second inhibitor of the sodium pump. J Biol Chem 1998; 273:784-792.

19 Kawamura A, Guo J, Itagaki Y, Bell C, Wang Y, Haupert GT Jr, et al. On the structure of endogenous ouabain. Proc Natl Acad Sci USA 1999; 96:6654-6659.

20 Laredo J, Hamilton BP, Hamlyn JM. Ouabain is secreted by bovine adrenocortical cells. Endocrinology 1994; 135:794-797.

21 Boulanger BR, Lilly MP, Hamlyn JM, Laredo J, Shurtleff D, Gann DS. Ouabain is secreted by the adrenal gland in awake dogs. Am J Physiol 1993; 264:E413-E419.

22 Manunta P, Rogowski AC, Hamilton BP, Hamlyn JM. Ouabain-induced hypertension in the rat: relationships among plasma and tissue ouabain and blood pressure. J Hypertens 1994; 12:549-560.

23 Blaustein MP. Physiological effects of endogenous ouabain: control of intracellular $\mathrm{Ca}^{2+}$ stores and cell responsiveness. Am J Physiol 1993; 264:C1367-C1387.

24 Liu J, Tian J, Haas M, Shapiro Jl, Askari A, Xie Z. Ouabain interaction with cardiac $\mathrm{Na} / \mathrm{K}$-ATPase initiates signal cascades independent of changes in intracellular $\mathrm{Na}$ and $\mathrm{Ca}$ concentrations. J Biol Chem 2000; 275:2783827844.

25 Dmitrieva RI, Doris PA. Ouabain is a potent promoter of growth and activator of ERK1/2 in ouabain-resistant rat renal epithelial cells. $J$ Biol Chem 2003; 278:28160-28166.

26 Abramowitz J, Dai C, Hirschi KK, Dmitrieva RI, Doris PA, Liu L, Allen JC. Ouabain- and marinobufagenin-induced proliferation of human umbilical cord vein smooth muscle cells and rat vascular smooth muscle cell line A7r5. Circulation 2003; 108:3048-3053.

27 Rossoni LV, Xavier FE, Moreira CM, Falcochio D, Amanso AM, Tanoue CU, et al. Ouabain-induced hypertension enhances left ventricular contractility in rats. Life Sci 2006; 79:1537-1545.

28 Jiang $X$, Ren YP, Lv ZR. Ouabain induces cardiac remodeling in rats independent of blood pressure. Acta Pharmacol Sin 2007; 28:344-352.

29 Hamlyn JM, Blaustein MP, Bova S, DuCharme DW, Harris DW, Mandel F, et al. Identification and characterization of a ouabain-like compound from human plasma. Proc Natl Acad Sci USA 1991; 88:6259-6263.

30 Vakkuri O, Arnason SS, Pouta A, Vuolteenaho O, Leppaluoto J. Radioimmunoassay of plasma ouabain in healthy and pregnant individuals. $J$ Endocrinol 2000; 165:669-677.

31 Manunta P, Ferrandi M, Bianchi G, Hamlyn JM. Endogenous ouabain in cardiovascular function and disease. J Hypertens 2009; 27:9-18.

32 Bauer N, Muller-Ehmsen J, Kramer U, Hambarchian N, Zobel C, Schwinger $\mathrm{RHG}$, et al. Ouabain-like compound changes rapidly on physical exercise in humans and dogs: effects of beta-blockade and angiotensin-converting enzyme inhibition. Hypertension 2005; 45:1024-1028.

33 Pitzalis MV, Hamlyn JM, Messaggio E, lacoviello M, Forleo C, Romito R, et al. Independent and incremental prognostic value of endogenous ouabain in idiopathic dilated cardiomyopathy. Eur J Heart Failure 2006; 8:179-186.

34 Ferrari P, Ferrandi M, Valentini G, Bianchi G. Rostafuroxin: an ouabain antagonist that corrects renal and vascular $\mathrm{Na}^{+}-\mathrm{K}^{+}$-ATPase alterations in ouabain and adducin-dependent hypertension. Am J Physiol Regul Integr Comp Physiol 2006; 290:R529-R535. 